\title{
Filosofia Problematizante: A versão Bergson-Deleuziana
}

[Problematizing Philosophy: The Bergson-Deleuzian Version]

\section{Paulo César Rodrigues®}

\begin{abstract}
Resumo: A ambição deste artigo é a de tematizar, no âmbito da filosofia, a proposta de um pensamento problematizante, tendo como ponto de partida as considerações bergson-deleuzianas sobre a noção de problema filosófico. Assumem-se aqui, portanto, as perspectivas de Bergson e Deleuze - ou ainda, a leitura deleuziana da noção de "problema", tal como figura na filosofia de Bergson - como uma única e mesma compreensão da atividade filosófica, a partir da qual se poderia cogitar uma nova postura pedagógica no domínio do ensino de Filosofia, seja na Universidade, seja na Educação Básica.
\end{abstract}

Palavras-chave: Bergson; Deleuze; educação; pedagogia problematizante; problema.

Abstract: The objective of this article is to discuss, within the scope of philosophy, the notion of problematizing thought, taking the Bergsonian-Deleuzian considerations of the notion of philosophical problem as starting point. We thus assume here that the perspectives of Bergson and Deleuze (taking account of the Deleuzian reading of the notion of 'problem' as it appears in Bergson's philosophy) are one and the same as regards the understanding of philosophical activity, and argue that on this basis a new pedagogical stance may be developed for the teaching of philosophy in both basic and academic education.

Keywords: Bergson; Deleuze; education; problematizing pedagogy; problem.

problematizante..$^{1}$ Em 1953, Heidegger concluiu sua meditação so-

$\mathrm{Na}$ perspectiva bergson-deleuziana, a melhor caracterização da filosofia é a que a concebe como uma atividade essencialmente bre a técnica moderna com uma sentença que bem poderia ser atribuída a Bergson ou a Deleuze "Pois o questionar é a devoção

\footnotetext{
*Professor Assistente Doutor da Universidade Estadual Paulista "Júlio de Mesquita Filho" (UNESP), Campus de Marília. Doutor em Filosofia pela Universidade Federal de São Carlos (UFSCar). E-mail: paulo.rodrigues@marilia.unesp.br. ORCID: https://orcid.org/0000-0002-2547-3731.

${ }^{1}$ É bem verdade que essa unidade bergson-deleuziana que aqui se propõe é, em certa medida, uma mera estratégia de abordagem. Zourabichvili (2009) nota que Deleuze pensou o problema "depois e para além de Bergson", dando a essa categoria um sentido fundamental: pedagógico, epistemológico e ontológico. Entretanto, do ponto de vista assumido neste artigo, os desenvolvimentos e aprofundamentos deleuzianos não alteram a caracterização do problema filosófico feita por Bergson, apenas a prolongam para além de onde Bergson pôde levá-la.
} 
do pensamento" (1997, p. 93) -, na medida em que a atitude "questionante" não se distancia ou, ao menos, não deve se distanciar da atitude "problematizante", tal como foi pensada pelos autores franceses. ${ }^{2}$ Considerar a problematização como ponto de partida, como a própria estrutura do pensamento filosófico, significa reconhecer que a tarefa do trabalho do pensamento é uma constante colocação e recolocação de problemas, mais ainda do que um debruçar-se sobre soluções teoricamente viáveis. Se o problema figura como seu núcleo vivo, não cabe mais, no âmbito da filosofia, exercer a razão construindo uma argumentação sensata sobre a realidade, por meio da concatenação de proposições, sóbrios registros de estados de coisas (cf. DELEUZE; GUATTARI, 1992). A filosofia, pois, torna-se indissociável da atividade de questionar ou de problematizar o real, torna-se o próprio desenvolvimento de questões ou problemas: “[...] tem-se, assim, essa escrita que nada mais é do que a questão O que é escre- ver? Ou essa sensibilidade que é apenas $\mathrm{O}$ que é sentir? E esse pensamento, $\mathrm{O}$ que significa pensar?" (DELEUZE, 2006, p. 277). Assim, em vez de se dedicar às respostas, a filosofia deve multiplicar as questões, desdobrar os problemas, como parte essencial de sua própria realização.

É certo que, por si só, semelhante atitude não traz nada de novo. Franklin Leopoldo e Silva, em seu belo livro sobre Bergson (1994), faz notar que o questionamento bergsoniano dos próprios problemas filosóficos não é nenhuma novidade na história da filosofia. Na verdade, desde as inquirições de Sócrates, passando pela dialética platônica, pela dúvida cartesiana, pelo kantismo etc., a filosofia sempre incidiu sobre os problemas teóricos, de modo que essa relação entre filosofia e problema seria quase um truísmo, já que ninguém mobilizaria o pensamento, em direção alguma, sem que um problema o incomode ou o limite. No caso específico de Kant, pondera Franklin Leopoldo e Silva, a reflexão

\footnotetext{
${ }^{2}$ Em Diferença e repetição, de 1968, na seção "Problema e questão", Deleuze pontua, é bem verdade, que é preciso determinar a diferença entre o problema e a questão. Todavia, ao identificar naquilo que chama de "pensamento moderno" uma índole essencialmente problematizante ou questionante (nas artes, na filosofia, etc.), declara que isso não significa "[...] a aplicação de um método de dúvida generalizada, não é o signo de um ceticismo moderno, mas, ao contrário, a descoberta do problemático e da questão como horizonte transcendental, como foco transcendental que pertence de maneira 'essencial' aos seres, às coisas, aos acontecimentos." (DELEUZE, 2006, p. 276). Sem dúvida, a filosofia de Heidegger é um pano de fundo importante na primeira obra autoral de Deleuze, mas suas elaborações sobre a noção de "problema" começaram, na verdade, em seu estudo sobre Bergson, de 1966. Cf., nesse sentido, o primeiro capítulo de Bergsonismo, p. 07-26; e também, ZOURABICHVILI, O vocabulário de Deleuze, verbete "problema", p. 89-94.
} 
transcendental mostrou toda uma constelação de problemas teóricofilosóficos que deveria ser afastada do âmbito do saber objetivo (os problemas metafísicos). Esse ponto é decisivo para determinar a distância entre Kant e Bergson, indicando, particularmente, a posição de Bergson frente à noção de "problema".

Com efeito, em Bergson, não há distinção entre saber objetivo (ciência) e saber não objetivo (metafísica), no sentido kantiano dos termos, justamente porque não existem problemas insolúveis, como Kant acreditou serem os problemas da metafísica, inacessíveis à razão teórica. Assim, a novidade de Bergson não está no fato de se tematizar os problemas filosóficos em primeiro lugar, mas no fato de se reconhecer que não existem problemas insolúveis, no fato de elaborar um método de dissolução de problemas ditos insolúveis, mostrando que, na verdade, são pseudoproblemas. Um problema insolúvel é, invariavelmente, ou um contrassenso ou um falso problema, isto é, um problema mal colocado, que, uma vez bem colocado, se resolveria por si só. Colocar bem um problema já é resolvê-lo. ${ }^{3}$ Esse é o ponto exemplarmente destacado por Deleuze, em sua leitura da filosofia de Bergson, de modo a não mais haver hiato entre a esfera do que se pode "conhecer" e a esfera do que se pode "pensar". Eis porque Bergson não precisou sacrificar a metafísica, pois não se curvou, como o fez Kant, à ideia de problemas insolúveis. 4

Partindo dessa confluência teórica, aqui chamada "bergsondeleuziana", e negligenciando deliberadamente as idiossincrasias dos dois pensadores, em outros aspectos, pretende-se esboçar uma reflexão sobre a natureza do problema filosófico e o impacto dessa concepção no plano do ensino de filosofia. As considerações seguintes devem ser recebidas, portanto, como notas introdutórias acerca de uma pedagogia problematizante em filosofia.

\section{II}

A abordagem bergson-deleuziana da noção de problema permite denunciar hábitos cognitivos demasiadamente enraizados, excessivamente utilizados e quase fa-

\footnotetext{
${ }^{3}$ Cf. BERGSON, a segunda Introdução a La pensée et le mouvant, p. 1303-1307.

${ }^{4}$ Se, como ainda será demonstrado, colocar um problema já é um ato do método, pode-se alegar que também nesse ponto Bergson se separa sensivelmente de Kant. Em Kant, a exposição do pensamento filosófico vem desacompanhada de uma reflexão sobre o método que melhor se presta a essa exposição, tema que já foi objeto dos protestos de Hegel (cf. ARANTES, 1994). Desse modo, o que a Crítica faz é separar pensamento filosófico e método. Em Bergson, ao contrário, o que se propõe é justamente uma fusão entre as duas instâncias.
} 
talmente imobilizadores do pensamento. Na filosofia, como nas demais produções da cultura, obstina-se em pensar as soluções, presumindo que os problemas do conhecimento, de uma maneira ou de outra, já estão dados, disponíveis à sanha especulativa da razão, embora ainda encobertos pelo manto de uma momentânea ignorância. O mérito de Bergson, na leitura de Deleuze, não foi o de ter retirado o manto que supostamente cobriria a cintilação dos problemas teóricos, mas o de ter mostrado que não há manto, simplesmente porque não há nada a encobrir, não há preexistência dos problemas. Os problemas são "inventados" tal como suas soluções. É a dimensão criativa da atividade do pensamento que os hábitos cognitivos tendem a obscurecer. E recuperar a centralidade do problema, na concepção bergson-deleuziana, quer dizer principalmente recuperar o elemento criador. Filosofar é criar "sentido", de modo que colocar um problema e mesmo resolvêlo é inventar, ampliar o "universo da significação", enriquecer o repertório teórico da filosofia. Deleuze notara, em seu livro sobre Hume: "A filosofia deve se constituir como a teoria do que fazemos, não como a teoria do que é." (DELEUZE, 2001, p. 151). Nesse sentido, a atividade filosófica não consiste em recobrir discursivamente um ser já dado, cuja estrutura e articulações caberia descrever paulatinamente; mas, antes, remete a uma produção humana, a um "fazer" humano; em uma palavra, a uma invenção, no sentido forte do termo. Antes de Deleuze, Bergson já dizia: "A invenção dá o ser ao que não era, podendo nunca ter vindo." (BERGSON, 2001b, p. 1293).

Atribuir ao pensamento filosófico essa potência criadora, essa atividade inventiva, coloca de imediato a seguinte questão: por que, então, não se filosofa precisamente da maneira sugerida por Bergson e Deleuze, isto é, lapidando livremente os problemas até o ponto milagroso em que eles se dissolvem em suas soluções? Ora, ocorre que a filosofia se encontra obcecada pelas soluções, assim como acontece nas matemáticas, nas ciências naturais, no domínio da técnica etc. O modelo predominante de saber objetivo é ainda o modelo da descoberta, um modelo heurístico, por assim dizer. Convém substituí-lo por uma compreensão inventiva da filosofia. Como se sabe, em um de seus últimos livros, em parceria com Guattari (1992), Deleuze busca definir a especificidade da filosofia exatamente dessa perspectiva criadora: a filosofia como "criação de conceitos" (DELEUZE; GUAT- 
TARI, 1992).5 No entanto, no campo da atividade cognitiva tradicional, trata-se ainda de descobrir soluções para problemas já postos. No caso da filosofia, para problemas milenares ou seculares (o problema do ser, dos universais, da relação mente e corpo, da liberdade etc.), Bergson ensinou que essa persistência é social e cultural, se não epistemológica e mesmo biológica. E Deleuze, interpretando Bergson, ressalta esse ponto em seu texto:

Esse preconceito é social (pois a sociedade, e a linguagem que dela transmite as palavras de ordem, dão-nos problemas totalmente feitos, como que saídos de "cartões administrativos da cidade", e nos obrigam a "resolvêlos", deixando-nos uma delgada margem de liberdade). Mais ainda, o preconceito é infantil e escolar, pois o professor é quem "dá" os problemas, cabendo ao aluno a tarefa de descobrir-lhes a solução. (DELEUZE, 1999b, p. 09) ${ }^{6}$

Tudo se passa, portanto, como se as razões de semelhante conduta teórica estivessem todas no plano pré-teórico, no contexto da formação social e educacional das pessoas. Ainda mais profundamente, tais razões assentam-se na constituição do aparelho cognitivo (um sistema de hábitos) e na própria história evolutiva da espécie: “[...] é a vida que se determina essencialmente no ato de contornar obstáculos, de colocar e resolver um problema. A construção do organismo é, ao mesmo tempo, colocação de problema e solução." (DELEUZE, 1999b, p. 10). A propósito, Bergson dá indicações precisas nessa direção, em L'évolution créatrice, apontando para a raiz biológica da noção de problema:

Uma coisa é a complica-

\footnotetext{
${ }^{5}$ É possível sustentar que a filosofia, enquanto saber historicamente constituído, sempre exercitou seu poder inventivo, a despeito dos hábitos que constrangem sua inventividade e a despeito de seu gosto pelas soluções. Quando Platão modifica os termos da ontologia de Parmênides, com o "parricídio" do diálogo Sofista, advém uma nova ontologia; quando Descartes instaura a "virada subjetiva", modifica-se completamente o enfoque sobre as questões epistemológicas; quando Kant inventa o "transcendental", nasce uma concepção original do sujeito etc. Nessa direção, cf. DELEUZE; GUATTARI, O que é a filosofia?

${ }^{6}$ Não é apenas interpretando Bergson que Deleuze recorre a esse tipo de comentário. Em Diferença e repetição, retoma a mesma observação: "É um preconceito infantil, segundo o qual o mestre apresenta um problema, sendo nossa a tarefa de resolvê-lo e sendo o resultado desta tarefa qualificado de verdadeiro e de falso por uma autoridade poderosa. E é um preconceito social, no visível interesse de nos manter crianças, que sempre nos convida a resolver problemas vindos de outro lugar e que nos consola, ou nos distrai, dizendo que venceremos se soubermos responder: o problema como obstáculo e o respondente como Hércules." (DELEUZE, 2006, p. 228).
} 
ção gradual de uma forma que se insere cada vez melhor no molde das condições exteriores, outra coisa a estrutura cada vez mais complexa de um instrumento que tira dessas condições um partido cada vez mais vantajoso. No primeiro caso, a matéria se limita a receber uma impressão, mas no segundo ela reage ativamente, resolve um problema. (BERGSON, 2001c, p. 554-555).

Assim, o erro de pensar os problemas do conhecimento como já dados e, além disso, imunes à aplicação dos valores lógicos verdadeiro ou falso, competindo aos pesquisadores unicamente rastrear as soluções, é um "preconceito" com raízes sociais e pedagógicas, epistemológicas e biológicas. Há uma resistência psíquica à invenção de problemas, porque o sujeito do conhecimento arrasta para o domínio teórico os hábitos da ação. E, no contexto da ação, os elementos manuseados, cumpre dizer, já estão dados. Bergson consagrou páginas célebres a esse tema, explorando-o exaustivamente em suas obras.7 Daí a necessidade de um esforço, de um verdadeiro espírito de rebeldia, para vencer as injunções dos hábitos e efetivamente elaborar os próprios problemas. Deleuze designará esse movimento do pensamento bergsoniano como um "método" filosófico.

Chega a ser chocante, à primeira vista, o capítulo inicial de Bergsonismo, cujo título é, justamente, "A intuição como método". Não é somente pelo teor paradoxal de sua proposta hermenêutica - pretender interpretar o imediato (intuição) através de mediações (método) -, mas sobretudo pela ousadia de se romper com a preexistência dos problemas e com sua pretensa imunidade lógica (a tradição sustenta que os problemas preexistem às soluções e que não são nem verdadeiros nem falsos, são colocados ou não colocados, resolvidos ou não resolvidos). Deleuze identifica em Bergson um gesto que julga genial: perceber que os próprios problemas filosóficos podem ser avaliados em termos de verdade ou falsidade. Se se têm dúvidas acerca da realidade da liberdade, da razoabilidade do movimento, da distinção de natureza entre o psíquico e o físico etc., não é apenas porque as soluções da-

\footnotetext{
${ }^{7}$ Cf. a esse respeito, BERGSON, Matière et mémoire, p. 179-181; 296-302; L'évolution créatrice, p. 519; 532-540; 611-635 e La pensée et le mouvant, p. 1257; 1294-1303.
} 
das tradicionalmente são inseguras, mas sobretudo porque se suspeita que os termos em que esses problemas foram colocados comprometem a qualidade da solução. Surge então a exigência de se repensar os problemas, criando uma nova abordagem da filosofia. Porém, isso não significa que os problemas se encontram todos já dados, prontos, aguardando passivamente a aplicação da curiosidade especulativa de algum filósofo, sagaz o bastante para fazer emergir as soluções. O primeiro ato do método que Deleuze acredita encontrar na intuição bergsoniana é, exatamente: "Aplicar a prova do verdadeiro e do falso aos próprios problemas, denunciar os falsos problemas, reconciliar verdade e criação no nível dos problemas." (DELEUZE, 1999b, p. 08).8 Os problemas serão finalmente conduzidos ao "tribunal da razão" ou, melhor dizendo, serão julgados em seus próprios termos, sozinhos, sem nenhuma referência às supostas soluções que receberam ao longo do tempo e que inevitavelmente os acompanham. É chegado o momento de saber se os problemas terão maturidade para suportar o teste da solidão.
A consequência imediata desse exercício de ousadia, constante na intuição metódica bergsoniana, é a "[...] determinação intrínseca do falso na expressão 'falso problema'." (DELEUZE, 1999b, p. 10). Ou seja, inspecionar os próprios problemas teóricofilosóficos implica reconhecer que eles mesmos podem ser intrinsecamente verdadeiros ou falsos, aquém de suas soluções. Implica, ademais, asseverar que, ao lado dos problemas verdadeiros, somente existem falsos problemas, jamais problemas insolúveis. É por isso que a crítica dos problemas filosóficos dispensa a crítica da razão e a consequente limitação do alcance do saber teórico. Talvez, o "vexame" da filosofia, por ainda não ter avançado na trilha do conhecimento rigoroso, se deva a sua contumaz cegueira em relação aos falsos problemas, que sempre supõe uma resoluta indiferença no tocante à atitude inventiva da própria filosofia, essa última inerente à ideia de pensamento problematizante. Decerto que todo o acervo de questões filosóficas, repelido pela Dialética Transcendental, poderia ser resgatado, no caso de os problemas

\footnotetext{
${ }^{8}$ Efetivamente, Deleuze desenvolveu a ideia segundo a qual a intuição bergsoniana é um método filosófico bem elaborado. Parodiando Descartes, enunciou as três "regras" do método intuitivo, as quais podem ser designadas como: 1 regra problematizante; 2 regra diferenciante e 3 regra temporalizante. Desse modo, a reflexão sobre o problema filosófico constitui o primeiro momento do método identificado por Deleuze no pensamento de Bergson. Cf. DELEUZE, Bergsonismo, p. 07-26.
} 
nela contidos puderem ser averiguados em si mesmos. Camille Riquier, em artigo recente no Brasil (2017) 9 , estipula que a filosofia de Bergson faz exatamente isso, retomando integralmente o projeto da metaphysica specialis, abandonado por Kant. Riquier conclui seu estudo indicando o seguinte:

Com efeito, se Kant permitiu definitivamente rejeitar a metafísica dogmática, há fortes chances de que a retomada intuitiva que Bergson opera não faça recair a nova metafísica nos defeitos da antiga, de sorte a não se identificar com nenhuma das posições já ocupadas e previamente condenadas por Kant, no quadro de sua dialética pura. É preciso, então, ir mais longe, e uma outra contribuição é necessária, se quisermos mostrar como a obra de Bergson segue passo a passo o programa de uma metafísica especial [...]. Kant havia, com efeito, apresentado ali um magnífico programa cujas promessas - declaradas insustentáveis - Bergson, com a intuição em proa, quis sustentar. (RIQUIER, 2017, p. 238).

No entanto, isso não significa que a recuperação do programa da metafísica especial, implodido pela primeira Crítica, se viabiliza em Bergson por meio de um simples retorno aos problemas da tradição, já exaustivamente ruminados. A retomada bergsoniana das questões da metafísica especial se dá graças à retomada da atitude problematizante em filosofia, como parte do próprio método intuitivo, explorado pelo filósofo no âmbito da especulação. Assim, são os problemas da liberdade, da matéria e de Deus que Bergson recoloca, modificando profundamente, através do exame crítico, a fisionomia desses problemas. 10

Como já foi indicado, o primeiro procedimento dessa postura problematizante consiste em aquilatar o problema teórico à luz de seu valor de verdade. Isso

\footnotetext{
${ }^{9}$ Trata-se do artigo "A superação intuitiva da metafísica: o kantismo de Bergson”, publicado na Revista Trans/Form/Ação, em 2017. Porém, esse texto foi originalmente publicado em francês: "La relève intuitive de la métaphysique: le kantisme de Bergson", em RIQUIER, Camille.; WORMS, Frédéric. Lire Bergson. Paris: PUF, 2011, p. 35-59. Utiliza-se aqui a versão brasileira, traduzida por Débora Cristina Morato Pinto.

${ }^{10}$ É assim que a "psicologia racional" é recuperada enquanto teoria da consciência como liberdade, em Essai sur les données immédites de la conscience; a "cosmologia racional" enquanto teoria da matéria como "ritmo de duração", em Matière et mémoire e L'évolution créatrice; e a "teologia racional" enquanto teoria de Deus como "emoção criadora", em Les deux sources de la morale et de la religion. Cf. RIQUIER, 2017, p. 238-239.
} 
não quer dizer, contudo, que "reconciliar verdade e criação no nível dos problemas" signifique pôr-se subitamente a criar problemas originais, cujo valor seria medido pelo vigor de sua inventividade. Quanto mais criativo, mais oportuno para a filosofia. Absolutamente! Nada mais distante da compreensão bergson-deleuziana. O que se solicita aqui é um exame cuidadoso dos próprios termos em que um problema teórico foi formulado; um remanejamento desses termos, denunciando sua incapacidade de manifestar a solução; ou ainda, mais frequentemente, uma verdadeira reelaboração do problema, desta vez viabilizando a solução. Como nota Deleuze (1999b), não se trata de determinar a verdade ou a falsidade do problema por meio da capacidade de receber ou não uma solução. ${ }^{11}$ Semelhante compreensão remeteria à ideia de problemas insolúveis, isto é, a falsidade do problema seria julgada como a "impossibilidade de receber uma solução". Na verdade, o que se busca é um meio de expor a inadequação dos termos nos quais o problema foi articulado, sem fazer referência às soluções historicamente dadas. $\mathrm{Na}$ concepção bergson-deleuziana, esse meio é divulgado através de uma "regra complementar" à primeira regra do método intuitivo:

Os falsos problemas são de dois tipos: "problemas inexistentes", que assim se definem porque seus próprios termos implicam uma confusão entre o "mais" $e$ o "menos"; problemas mal colocados, que assim se definem porque seus termos representam mistos mal analisados. (DELEUZE, 1999b, p. 10).

O primeiro tipo de falsos problemas Deleuze exemplifica com o repertório do negativo (cf. 1999b, p. 10-11); o segundo, com as miscelâneas conceituais que proliferam na ciência e na filosofia (a "grandeza intensiva", que mistura qualidade e quantidade; o complexo percepção-memória, que mistura matéria e espírito; a má compreensão da vida, que confunde o vital com o físico-químico etc.). Sem entrar, por enquanto, na exemplificação, compreendese que a regra complementar fornece as instruções fundamentais para se identificar o falso problema. Há sempre uma apre-

\footnotetext{
${ }^{11}$ Em Diferença e repetição, Deleuze chamará de "ilusão filosófica" o erro de julgar os problemas a partir das soluções; cf. DELEUZE, 2006, p. 232.
} 
ciação equivocada da noção de "diferença": das diferenças de grau, quando se confunde o mais com o menos ou o menos com o mais; das diferenças de natureza, quando se persevera em apreender o real como um "misto mal analisado".

Mais adiante, Deleuze mostrará que todas as dificuldades engendradas pelos falsos problemas, dificuldades aparentemente invencíveis, se vinculam sempre à insensibilidade em relação às diferenças de natureza, à tendência a reunir o real em ideias gerais, em feixes de coisas ou de representações, ligadas entre si pela semelhança. É preciso aprender a atentar para as diferenças. Eis um ensinamento que Deleuze encontra já em Bergson. Não é à toa que ele tenha declarado, em artigo de 1956, que "[...] o bergsonismo deve trazer a maior contribuição para uma filosofia da diferença" (DELEUZE, 1999a, p. 95), filosofia a qual se encarregaria pessoalmente de realizar uma década depois (em 1968, com Diferença e repetição). De fato, na perspectiva bergson-deleuziana, todo falso problema se enraíza na incapacidade de apreender as diferenças de natureza:

Em resumo, toda vez que se pensa em termos de mais ou de menos, já fo- ram negligenciadas diferenças de natureza entre as duas ordens ou entre os seres, entre os existentes. Por aí se vê como o primeiro tipo de falso problema repousa em última instância sobre o segundo [...]. (DELEUZE, 1999b, p. 13).

Na medida em que pensar em termos de mais ou de menos é pensar no espaço, de acordo tão somente com diferenças de grau, pensar em termos de diferenças de natureza já é se aproximar da realidade fundamental do bergsonismo: da duração. Fica visível, aqui, a relação interna entre os três momentos do método intuitivo (problematizante, diferenciante e temporalizante), uma vez que colocar sob suspeita a legitimidade dos problemas teóricos induz o pensamento a respeitar as diferenças de natureza, presentes nos elementos que compõem o real. Isso quer dizer, de um só golpe, estancar a proliferação de falsos problemas, por meio da aplicação da regra de diferenciação (purificação da experiência através da separação das "presenças puras" ou "tendências puras" que a constituem necessariamente como "misto") e da regra temporalizante (pensar os problemas no tempo e não mais no espaço), posto que aplicar a regra diferenciante significa ao mesmo 
tempo apreender o real à luz das diferenças de natureza, isto é, apreender o próprio "movimento da diferença”, a própria duração (durée). Nesse momento, o método intuitivo se encontra inteiramente percorrido. Os três atos do método se interiorizam e iluminam o itinerário para o imediato: para "penser en durée", dirá Bergson (2001b, p. 1275); para o "gozo da diferença", dirá Deleuze (1999b, p. 97).

Adotando agora um exemplo concreto, para melhor ilustrar a ideia bergson-deleuziana de método problematizante em filosofia, pode-se considerar o problema do movimento, tal como aparece na tradição filosófica, isto é, na Grécia pré-socrática, com Zenão de Eleia. 12 É notável que, nos termos em que Zenão o propôs, sua solução é impossível. Zenão demonstra - através de pelo menos quatro paradoxos (paradoxo da flecha, de Aquiles e a tartaruga, do estádio e das filas em movimento) - que os movimentos que constatamos na natureza não podem receber uma explicação racional adequada. Embora a experiência permita testemunhá-los, não se consegue comprovar sua razoabilidade. Toda a dificuldade re- pousa, evidentemente, nos termos em que o problema foi colocado. Bergson faz notar que o modo como a tradição o equacionou foi essencialmente espacial. Nessa manobra da inteligência, o movimento - que é um ato temporal, porque ocorre sempre no interior de certa duração - foi projetado no espaço, reduzido a uma trajetória percorrida por um corpo móvel, o qual abandona uma posição inicial e atinge uma posição final, e, entre uma coisa e outra, percorre uma série de posições intermediárias. Acontece que todas essas posições são imóveis. Acreditase, então, que o movimento possa ser representado intelectualmente por certa quantidade de imobilidades distribuídas no espaço.

Todavia, esse ainda não é o componente que induziu Zenão a repelir o movimento do âmbito da verdade. O ponto fundamental encontra-se no fato de que há, de direito, entre duas posições quaisquer no espaço, divisibilidade infinita; por conseguinte, infinitas posições intermediárias. Como um corpo móvel pode percorrer, em um tempo finito, uma quantidade infinita de posições? A conclusão de Zenão de Eleia foi a de que o movimento é ra-

\footnotetext{
${ }^{12} \mathrm{O}$ problema do movimento, nos termos em que Zenão o colocou, figura nos textos bergsonianos em várias ocasiões; cf., particularmente, BERGSON, Essai sur les données immédiates de la conscience, p. $74-77$ e a primeira Introdução ao La pensée et le mouvant, p. 1258-1268.
} 
cionalmente inconcebível. A flecha nunca atinge seu alvo, pois, para fazê-lo, precisaria ultrapassar infinitas posições espaciais, o que é impossível. Bergson indicará, alhures, as lamentáveis consequências metafísicas dessa problematização eleata. ${ }^{13}$

Há paradoxo nessa questão, posto que uma coleção de imobilidades não pode engendrar o movimento, seu exato contrário. Há paradoxo, principalmente, porque o infinito não pode caber no finito. No entanto, como sempre, todo problema está na formulação do problema. No horizonte bergson-deleuziano, o erro de Zenão foi o de ter equacionado um evento temporal em termos espaciais. Essa tradução do temporal em espacial está na origem do problema do movimento e compromete irremediavelmente sua solução. Cumpre acrescentar, ademais, que semelhante tradução é viabilizada pelos hábitos de pensamento, pela já mencionada cegueira em relação às diferenças de natureza, mormente entre espaço e tempo. Solucionar o problema do movimento pela via inaugurada por Zenão é, de fato, impossível. Mas isso não significa que a filosofia deva se resignar a jamais conhecer a natureza do devir. Ao contrário, é preciso rever o modo como o problema foi formulado e, nessa operação, denunciá-lo como falso problema do tipo "problema mal colocado", posto que trabalha com um "misto mal analisado", não aplicando a regra de diferenciação, a qual separaria, no movimento, o elemento espacial (a trajetória percorrida) do elemento temporal (o ato simples, indivisível, de a percorrer). Na confusão do tempo com o espaço, da duração com a extensão, a escola de Eleia ensinou que somente uma unidade estática, eterna e imutável pode se proclamar como o lugar da verdade.

Conforme reconhece Deleuze, sem dúvida ainda acompanhando as teses de Bergson, "[...] a solução deriva necessariamente das condições completas sob as quais se determina o problema como problema, dos meios e dos termos de que se dispõe para colocá-lo." (DELEUZE, 2006, p. 229). Zenão, formado na escola de Eleia, comprometido com a ontologia de seu mestre Parmênides, só pôde dar ao problema do movimento uma formulação espacial, capaz de contradizê-lo racionalmente e assim servir aos interesses ideo-

\footnotetext{
${ }^{13}$ A consequência mais desastrosa dessa argumentação, na visão de Bergson, foi a expulsão do devir do domínio do ser, a opção eleata pela imobilidade, que marcará a metafísica grega de modo indelével. Cf., nesse ponto, a revisão crítica da metafísica, apresentada no último capítulo de L'évolution créatrice, especialmente p. 747-807.
} 
lógicos de sua orientação teórica. Diante de seus paradoxos, a filosofia posterior não deve inventar soluções mais engenhosas. A insolubilidade do problema, nos termos em que Zenão o colocou, a dissuade desse trabalho. Porém, essa insolubilidade tem a ver unicamente com a maneira como Zenão o colocou, a armadura na qual o encerrou. Retornar ao problema, exigência da primeira regra do método intuitivo, é a própria tarefa da filosofia como pensamento criador, rebelde a todo dogmatismo. Deleuze observa que é preciso superar os "preconceitos" que imobilizaram a filosofia - superar a "imagem dogmática do pensamento", a cristalização de representações ${ }^{14}$-, para recuperar o sentido genuíno do "ato de pensar":

É o destino da imagem dogmática do pensamento apoiar-se sempre em exemplos psicologicamente infantis, socialmente reacionários [...] para prejulgar o que deveria ser o mais elevado no pensamento, isto é, a gê- nese do ato de pensar e o sentido do verdadeiro e do falso. (DELEUZE, 2006, p. 228).

Nesse ponto, a noção de problema desempenha um papel fundamental. Enfatiza Zourabichvili: "Os problemas são atos que abrem um horizonte de sentido [...]" (ZOURABICHVILI, 2009, p. 90). Sem entrar no mérito da concepção de "conceito", em última análise indissociável da noção de problema (cf. DELEUZE; GUATTARI, 1992), pode-se cogitar aqui que a adoção de uma postura problematizante acarreta, nos dois pensadores, a recuperação da filosofia como disciplina criadora, produtora de sentido. Ao romper com a ideia de preexistência do problemático, exige-se da atividade do pensamento uma constante reinstauração do problema, abrindo para sua solução, a partir de um itinerário metódico descrito por Bergson e Deleuze como "intuitivo". E a intuição é, ao mesmo tempo, revisão crítica dos problemas da tradição e ato positivo de instauração de novos problemas ou de problemas reelabo-

\footnotetext{
${ }^{14}$ Nessa direção, Deleuze declarou: "Por não ver que o sentido ou o problema é extraproposicional, que ele difere, por natureza, de toda proposição, perde-se o essencial, a gênese do ato de pensar, o uso das faculdades." (DELEUZE, 2006, p. 226-227). E Bento Prado Júnior, comentando Deleuze no artigo "Plano de Imanência e vida", afirma: "Pensar não é determinar objetos - esta tarefa, que transforma o plano de imanência em sistema de estados de coisas, cabe à ciência. Pensar é jogar-se contra os limites da representação e subvertê-la. Se me permitem a insistência, pensar é liberar o fluxo da vida e expandir sua esfera." (PRADO JÚNIOR, 2004, p. 170).
} 
rados, reapresentados em novos termos, ou ainda, em termos de duração. Como não ver que pensar em duração já é acompanhar o movimento criador que constitui o real? Naturalmente, se o próprio real é "[...] criação contínua, jorro ininterrupto de novidade" (BERGSON, 2001b, p. 1259), o conhecimento que dele se pode obter tem de ser invenção.

\section{III}

A tradição filosófica jamais deve ser entendida como um reservatório de problemas, conceitos ou informações. O modo de se apropriar do passado da filosofia precisa ser suficientemente vivaz para superar até mesmo a ideia de criação filosófica como uma espécie de combinatória de signos, mero remanejamento de elementos preexistentes, ideia que volta ao proscênio da filosofia com o estruturalismo (uma teoria seria como um arranjo atual de um repertório virtual de relações). ${ }^{15}$
Assim, presume-se que essa pedagogia problematizante, ${ }^{16}$ extraída dos mencionados pensadores franceses, deva ser acolhida sobretudo como uma nova atitude, e não como um receituário metodológico previamente elaborado e ostensivamente recomendado aos filósofos. Por pedagogia problematizante se pretende designar um tipo de relação com a filosofia que assume a categoria do problemático como o ponto inicial da atividade do pensamento teórico. Conforme se tentou mostrar acima, semelhante proposta está contida explicitamente na concepção bergson-deleuziana de método intuitivo. E, por atitude, entende-se aqui uma certa relação com o movimento do pensamento, colocando-se em sintonia com esse movimento por meio de um esforço de coincidência com a própria "gênese do pensar".

Mais exatamente, trata-se de projetar a reflexão acerca do problema filosófico - tal como extraída da intuição metódica

\footnotetext{
${ }^{15}$ No texto "Em que se pode reconhecer o estruturalismo?", acompanhando Lévi-Strauss, Deleuze pensa a estrutura como um "repertório ideal" que contém, virtualmente, uma totalidade finita de elementos em coexistência. Uma língua realmente falada por algum povo, uma regra matrimonial efetivamente aplicada por uma sociedade, um determinado tipo de produção econômica, empiricamente constatável em um momento histórico etc. seriam manifestações positivas, locais, de um campo virtual mais vasto, exprimindo nessas configurações empíricas uma atualização parcial de componentes estruturais preexistentes. Destaca Deleuze: “[...] Lévi-Strauss frequentemente apresenta a estrutura como uma espécie de reservatório ou de repertório ideal, onde tudo coexiste virtualmente, mas onde a atualização se faz necessariamente segundo direções exclusivas, implicando sempre combinações parciais e escolhas inconscientes. Extrair a estrutura de um domínio é determinar toda uma virtualidade de coexistência que preexiste aos seres, aos objetos e às obras desse domínio. Toda estrutura é uma multiplicidade de coexistência virtual." (DELEUZE, s/d, p. 283).

${ }^{16}$ Não é o objetivo desse artigo traçar paralelos ou mesmo relacionar a pedagogia problematizante, aqui tematizada, com a "pedagogia do conceito", tal como desenvolvida por Deleuze e Guattari. Cf., nesse sentido, O que é a filosofia?, de Deleuze e Guattari, e Elementos para a leitura de textos filosóficos, de Frédéric Cossutta.
} 
bergson-deleuziana -, sobre o campo do ensino de filosofia, seja na Educação Básica, seja na Universidade, averiguando quais consequências poderiam ser daí inferidas. A primeira e a mais importante delas é, sem dúvida, uma inevitável tensão com o modus operandi vigente no ensino da disciplina: a centralidade historiográfica. De fato, propor uma abordagem problematizante da filosofia sempre resultará em um acerto de contas com o enfoque historiográfico, amplamente difundido no Brasil, por conta de conhecidas contingências históricas (as "missões francesas", que instruíram as primeiras turmas de graduados em Filosofia no país, bem como a penetração do "método" de leitura de textos filosóficos trazido por elas).17

Contudo, a pedagogia problematizante, inferida da concepção bergson-deleuziana acerca da natureza do trabalho filosófico, exibe, curiosamente, relações acentuadas com o chamado método "estrutural"18 de leitura, o qual está na própria base da obsessão historiográfica em filosofia. Igualmente saído do espiritualismo francês (MARQUES, 2007), o método estrutural consiste em buscar reconstituir a "ordem por razões", isto é, o "tempo lógico" que organiza os enunciados de uma doutrina filosófica em um sistema, pouco se importando com a verdade material de tais enunciados (sua adequação a estados de coisas ou sua simetria com o mundo). Com isso, ocupava-se em conferir rigor científico aos procedimentos de pesquisa do historiador da filosofia, à medida que a estrutura lógica (necessária) da obra passa a ser visível, graças ao trabalho do intérprete (GOLDSCHMIDT, 1970). O sucesso dessa "regra de interpretação", no âmbito da pesquisa acadêmica, não deixou de afetar o ensino, inflacionando a ideia segundo a qual a única relação séria com a filosofia é a que consagra a história da filosofia como núcleo formativo, desde que lida a partir das indicações metodológicas goldschmidtianas. A consequência prático-

\footnotetext{
${ }^{17}$ Sabe-se que, no Brasil, a formação da filosofia universitária, no contexto laico, deu-se a partir de 1935, com a criação da USP e do primeiro curso propriamente acadêmico de Filosofia. Por conta da forte presença de professores franceses, como Jean Maugüe, Victor Goldschmidt, Martial Guéroult, Gérard Lebrun etc., a principal característica do ensino da filosofia passou a ser o estudo meticuloso de textos filosóficos clássicos, aplicando o método "estrutural" de leitura (GOLDSCHMIDT, 1970). Assim, a historiografia da filosofia passou a ocupar o próprio lugar da filosofia no Brasil, e o comentário, o lugar das teses, acarretando uma "falta de assunto crônica" que, segundo Paulo Arantes, esterilizou a imaginação teórica brasileira (ARANTES, 1994).

${ }^{18}$ Cumpre registrar, de imediato, que o termo "estrutural" não remete, aqui, ao estruturalismo, sendo antes "[...] a derradeira figura do velho espiritualismo universitário francês, com o qual rompera o que havia de mais vivo na filosofia francesa do pós-guerra." (ibid., p. 17).
} 
pedagógica mais imediata dessa postura foi a abolição dos manuais e a adoção de cursos monográficos que visavam unicamente à explicitação da estrutura de uma obra clássica.

Como se vê, o ponto de contato entre a concepção problematizante e a concepção historiográfica é a indiferença em relação à verdade material das asserções filosóficas. ${ }^{19}$ É bem verdade que, no caso da proposta problematizante, a abolição da verdade se dá de modo muito mais manifesto em Deleuze do que em Bergson, com a ideia da filosofia como conhecimento extraproposicional (DELEUZE, 1992, 2006). Ainda assim é possível sustentar que, nos dois casos (nas concepções problematizante e historiográfica), a filosofia é pensada como uma atividade não referencial, como uma elaboração que não pretende registrar estados fáticos (tarefa científica e não filosófica). Em Berg- son e Deleuze, trata-se de construir sentido, reelaborando-se os problemas teóricos; já na historiografia francesa, trata-se de expor a arquitetura lógica que constitui a ossatura do discurso filosófico, sem se inquietar com a capacidade dessa arquitetura espelhar a estrutura do real.20

Se teoria é um sistema de signos que remete aos objetos, de modo que sua veracidade pode ser controlada pelo próprio mundo externo, então a filosofia não é teoria, posto que não descreve estados de coisas. ${ }^{21}$ Apesar de ser indiscutível que semelhante concepção arrasta a filosofia para o campo da literatura, nem por isso ela se reduz a uma mera expressão estética da realidade, uma vez que possui um "sentido" que preserva a intenção cognitiva. Um enunciado filosófico, ao contrário de um verso, por exemplo, não é um jogo fonético, semântico, sintático ou mesmo visual

\footnotetext{
${ }^{19}$ Outro ponto em comum é o apelo à intuição: no caso da historiografia francesa, para justificar a perenidade da obra, de modo que sua verdade histórica jamais poderia ser contestada (GOLDSCHMIDT, 1970; ARANTES, 1994); no caso da versão bergson-deleuziana, para desfazer os problemas filosóficos no próprio ato de pensá-los temporalmente.

${ }^{20}$ Paulo Arantes lembra que essa concepção da filosofia está presente em pelo menos dois dos célebres franceses que participaram das missões: "O que dizia Lebrun? Isto mesmo, que a filosofia existe mas não ensina verdades (como de resto queria seu compatriota e colega uspiano, G.-G. Granger), que não é 'teoria', não está amarrada a nenhum referente e mesmo assim, não informando sobre nada, não é vazia de sentido - e que tudo isso não obstante não é redutível à 'escritura' absolutamente intransitiva da literatura, à pura ressonância dos signos etc." (ARANTES, 1994, p. 196).

${ }^{21}$ Ainda segundo Paulo Arantes, Lebrun redundou em uma concepção da filosofia como “[...] 'reflexão' da linguagem sobre ela mesma” (ibid., p. 196), enquanto Granger abraçou a concepção da filosofia como uma apreensão da "totalidade da experiência" (GRANGER, 1994).

${ }^{22}$ A noção de "sentido" receberá amplos desenvolvimentos na filosofia de Deleuze (cf. DELEUZE, 2011). Porém, já em Diferença e repetição, Deleuze declarou: “O sentido está no próprio problema" (2006, p. 226). E, um pouco antes, observara: "[...] a significação remete apenas ao conceito e à maneira pela qual ele se refere a objetos condicionados num campo de representação; mas o sentido é como a Ideia que se desenvolve nas determinações
} 
com as palavras, mas o registro de um sentido.22 Talvez seja oportuno recordar aqui a frase de Jung: "O pêndulo do espírito oscila entre sentido e não-sentido e não entre verdadeiro e falso." (JUNG, s/d, p. 139). Quando Deleuze menciona a atitude problematizante como um "horizonte transcendental", sugere que a filosofia é um discurso que se dirige às condições de todo discurso. Nessa direção, problematizar é resgatar as condições originárias do pensar, o ato inicial de criação de sentido.

Na leitura de Deleuze, Bergson fizera isso consultando a própria tradição, denunciando seus percalços, reinventando seus problemas. Ainda que tenha considerado o problema como passível de ser verdadeiro ou falso, verdade e falsidade não foram empregadas no mesmo sentido da tradição (adaequatio intellectus et rei). A primeira regra do método bergsoniano não ensina a reconhecer a verdade de um problema confrontando-o com o mundo. Como se sabe, o problemático não se enuncia numa proposição declarativa. Ao que tudo indica, a primeira regra ensina, por um lado, a expulsar os falsos problemas, identificando-os justamente na negligência das diferenças de natureza; por outro, reinstaura os problemas da filosofia, ao assumir a tarefa do pensamento como criação, penser en durée. Conforme nota Zourabichvili, a concepção bergson-deleuziana estabelece "[...] uma nova postura do pensamento, abrindo uma perspectiva inabitual sobre o mais familiar ou conferindo interesse a dados até então reputados insignificantes." (ZOURABICHVILI, 2009, p. 90). Nesse momento, reinventam-se os problemas, o que também remete aos outros dois atos do método: diferenciação e temporalização do pensar (pensar o real como processo e não como coisa). Assim, começar pelo problema é começar pelo começo. É, em Bergson e Deleuze, retornar à origem do pensamento. Deveras, só se pensa a partir de problemas.

Resta saber como operacionalizar essa concepção profunda da filosofia no contexto do ensino. E essa seria a segunda e última consequência que se retira da intuição metódica bergson-deleuziana. Como se vê, a dificuldade é extrema, posto que retornar à gênese questionante do pensar envolve já uma ampla familiaridade com o pensar. A técnica de leitura da historiografia francesa ao me-

sub-representativas." (ibid., p. 223). Daí se vê o quanto a parte propositiva da filosofia de Deleuze é dependente de uma crítica radical das filosofias da representação. 
nos fornecia um método de trabalho rigoroso. Quanto à pedagogia problematizante, o que dizer?

De início, julga-se pertinente uma metodologia de estudo filosófico como a que foi proposta por Mario Ariel González Porta (2007), no livro A filosofia a partir de seus problemas. Ainda que aí se trate de pensar o problema como um elemento já dado pelo próprio filósofo, explícita ou implicitamente, de modo que o trabalho exegético se reduziria a uma identificação quase mecânica de estruturas textuais (o problema, a tese, os argumentos etc.), sem remontar ao ato originário do pensamento problematizante, acredita-se que semelhante proposta tem a vantagem de conceber a filosofia como uma atividade sempre mobilizada por questões muitas vezes angustiantes, evitando apreendêla como a remontagem de uma "cadeia de razões". No plano do ensino, da prática formativa propriamente dita, cogita-se que a única maneira de operacionalizar a pedagogia problematizante é, em um primeiro momento, incidindo sobre os próprios problemas da tradição, aprendendo a ler a filosofia a partir de seus problemas, desenvolvendo uma verdadeira "competência" no trato com todo tipo de impasse teórico. Em um segundo momento, caberia aprofundar essa relação com o problema ou, melhor dizendo, a relação do problema com a solução (tese e argumentos), tal como essa relação se estabelece na obra filosófica examinada pelo estudante. As relações internas entre o problema teórico, a tese sustentada e os argumentos convocados para sustentá-la tecem a estrutura da obra e cabe ao aprendiz explicitá-la. Pode-se alegar que o que se obtém com isso é ainda uma estrutura lógica, uma "retradução lógica" (PORTA, 2007, p. 71-73), muito análoga à "arquitetura" da historiografia francesa tradicional. Contudo, como sempre, vale a pena atentar para as diferenças.

É preciso reconhecer que, na historiografia estrutural, o problema não era um elemento relevante. Buscava-se o tempo lógico operando no interior do sistema, distribuindo sucessiva e verticalmente os enunciados, visto que eles não se situam todos no mesmo nível (de fato, existem, também em filosofia, princípios, hipóteses, consequências etc.). Já no caso de um ensino problematizante, deve haver um exercício de perseguição dos problemas, de pensar a tese sempre em relação ao problema. Sem dúvida, tudo isso exprime o momento propedêutico dessa proposta pedagógica, o qual eventualmente poderia recobrir o ensino de filosofia no 
âmbito da Educação Básica. Porém, é preciso avançar e efetivamente questionar o problema teórico nele mesmo. É essa operação o sentido genuíno da pedagogia problematizante. Colocar em questão a questão. Problematizar o problema. E aqui não se trata de mero jogo de palavras.

Conforme se tentou mostrar nesse artigo, um método problematizante radical, como o que foi apresentado por Bergson e Deleuze, deve sempre estabelecer uma relação polêmica com os problemas tradicionais, deve depurálos, para fazer eclodir a solução. E, na medida em que pensar os problemas já é colocar-se no próprio interior da atitude filosófica, na "gênese do ato de pensar", é possível afirmar que uma pedagogia problematizante se apresenta como um caminho promissor para o surgimento de uma reflexão teórica autônoma e revisionista, isto é, capaz de alterar a imagem que até então se fazia do trabalho do pensamento.

Por fim, se uma relação meramente historiográfica com a fi- losofia normalmente desaba em um saber que degenera em erudição, uma relação problematizante exibe condições mais favoráveis para lançar o pensamento à frente de si mesmo, introduzindo novidade no campo do conhecimento, na medida em que desafia o pensador a romper os limites de sua atual compreensão do mundo.

Decerto que essas considerações pedagógicas são demasiadamente apressadas para oferecerem uma proposta mais segura no âmbito do ensino de Filosofia, exigindo um estudo aprofundado de diversos pontos, para dar conta de explorar, em seus pormenores, as relações e as distinções entre o enfoque historiográfico e a abordagem problematizante. Contudo, nesse artigo, o que se pretendeu elaborar foi apenas uma reflexão preliminar, visivelmente introdutória, sobre o teor inovador da proposta bergson-deleuziana no contexto da Educação. Desenvolvimentos ulteriores dessa reflexão poderão determinar o valor das considerações aqui apresentadas. 


\section{Referências}

ARANTES, Paulo Eduardo. Um departamento francês de ultramar: estudos sobre a formação da cultura filosófica uspiana. São Paulo: Paz e Terra, 1994.

BERGSON, Henri. Essai sur les données immédiates de la conscience. In: Euvres (Édition du centenaire). Paris: PUF, 2001a.

BERGSON, Henri. La pensée et le mouvant. In: CEuvres (Édition du centenaire). Paris: PUF, 2001b.

BERGSON, Henri. L'évolution créatrice. In: Euvres (Édition du centenaire). Paris: PUF, 2001c.

BERGSON, Henri. Matère et mémoire. In: Euvres (Édition du centenaire). Paris: PUF, 2001d.

COSSUTTA, Frédéric. Elementos para a leitura de textos filosóficos. São Paulo: Martins Fontes, 1994.

DELEUZE, Gilles. A concepção da diferença em Bergson. In: DELEUZE, Gilles. Bergsonismo. Tradução de Luiz B. L. Orlandi. São Paulo: Editora 34, 1999a. p. 95-123.

DELEUZE, Gilles. Bergsonismo. Tradução de Luiz B. L. Orlandi. São Paulo: Editora 34, 1999b.

DELEUZE, Gilles. Empirismo e subjetividade: ensaio sobre a natureza humana segundo Hume. Tradução de Luiz B. L. Orlandi. São Paulo: Editora 34, 2001.

DELEUZE, Gilles. Diferença e repetição. Tradução de Luiz B. L. Orlandi e Roberto Machado. Rio de Janeiro: Graal, 2006.

DELEUZE, Gilles. Lógica do sentido. Tradução de Luiz Roberto Salinas Fortes. São Paulo: Perspectiva, 2011.

DELEUZE, Gilles. Em que se pode reconhecer o estruturalismo? In: CHÂTELET, François. História da filosofia: ideias e doutrinas, O século XX. Tradução de Hilton Japiassu. Rio de Janeiro: Zahar, s/d. p. 271-303.

DELEUZE, Gilles; GUATTARI, Félix. O que é a filosofia? Tradução de Bento Prado Jr. e Alberto Alonso Muñoz. São Paulo: Editora 34, 1992.

GOLDSCHMIDT, Victor. Tempo histórico e tempo lógico na interpretação dos sistemas filosóficos. In: GOLDSCHMIDT, Victor. A religião de Platão. São Paulo: Difusão Europeia do Livro, 1970. p. 139-147.

GRANGER, Gilles-Gaston. A ciência e as ciências. Tradução de Roberto Leal Ferreira. São Paulo: UNESP, 1994.

HEIDEGGER, Martin. A questão da técnica. Tradução de Marco Aurélio Werle. São Paulo: Cadernos de Tradução, Departamento de Filosofia USP, 1997.

JUNG, Carl Gustav. Memórias, sonhos, reflexões. Tradução de Dora Ferreira da Silva. Rio de Janeiro: Nova Fronteira, s/d.

MARQUES, Ubirajara Rancan de Azevedo. A escola francesa de historiografia da filosofia. São Paulo: UNESP, 2007.

PORTA, Mario Ariel González. A filosofia a partir de seus problemas. São Paulo: Loyola, 2007.

PRADO JÚNIOR, Bento. Plano de imanência e vida. In: PRADO JÚNIOR, Bento. Erro, ilusão, loucura: ensaios. São Paulo: Editora 34, 2004. p. 139-170.

RIQUIER, Camille. A superação intuitiva da metafísica: o kantismo de Bergson. Trans/Form/Ação, Marília, v. 40, n. 2, p. 217-42, 2017.

SILVA, Franklin Leopoldo e. Bergson: intuição e discurso filosófico. São Paulo: Loyola, 1994.

ZOURABICHVILI, François. O vocabulário de Deleuze. Tradução de André Telles. Rio de Janeiro: Relume Dumará, Sinergia, Ediouro, 2009.

Recebido: $28 / 09 / 2019$

Aprovado: $28 / 11 / 2019$

Publicado: $26 / 01 / 2020$ 